\title{
Urinary Kidney Injury Molocule-1 Level in Preterm Neonates with Respiratory Distress Syndrome
}

\author{
Maha Youssef ${ }^{1}$, Manal Abdelsalam ${ }^{1 *}$, \\ Radwa Saeed2', Alshimaa Mohamed1 \\ ${ }^{1}$ Department of Pediatrics, Faculty of Medicine (Girls), Al-Azhar University, Cairo, Egypt \\ ${ }^{2}$ Department of Clinical Pathology, Faculty of Medicine (Girls), Al-Azhar University, Cairo, Egypt \\ Email: "manal24969@gmail.com
}

Received 24 November 2015; accepted 29 February 2016; published 3 March 2016

Copyright (C) 2016 by authors and Scientific Research Publishing Inc.

This work is licensed under the Creative Commons Attribution International License (CC BY). http://creativecommons.org/licenses/by/4.0/

c) (i) Open Access

\section{Abstract}

Background: Despite recent advances in perinatal and neonatal care in respiratory distress syndrome (RDS) prevention and treatment, a considerable number of these neonates suffer from acute kidney injury (AKI), and it is associated with poor outcome as an independent risk factor. KIM-1 mRNA and protein are expressed at a low level in normal kidney but are increased in post ischemic kidney. Aim: The aim is to detect the value of urinary KIM-1 measurement as an early predictor marker of acute kidney injury in preterm neonates with respiratory distress syndrome. Patients and methods: The study included 30 preterm newborn with (RDS) $\leq 36$ weeks during the period from October 2014 to March 2015. Also the study included 30 apparently healthy newborn $\leq 36$ weeks as controls. They were selected from NICU of Manshiate Elbakry hospital Cairo, Egypt. uKIM-1 along with serum creatinine levels and eGFR were assessed in days 1 of life for both groups and in day 3 for cases. Results: In day one of life, we found a significant increase in uKIM-1 levels in preterm newborn with RDS compared to their controls $(2.88 \pm 1.01 \mathrm{ng} / \mathrm{ml}$ and $0.95 \pm 0.52$ $\mathrm{ng} / \mathrm{ml}$ respectively $(\mathrm{p}=\mathbf{0 . 0 0 1})$ ). There is no significant difference between both groups regarding serum creatinine and eGFR. In day 3 of life, preterm with RDS had significant decrease in uKIM-1 levels compared to day 1 of life with significant increase in non-survivor compared to survivor group ( $2.30 \pm 1.56 \mathrm{ng} / \mathrm{ml}$ and $1.30 \pm 0.90 \mathrm{ng} / \mathrm{ml}$ respectively $(p=0.03)$ ). The sensitivity and specificity of uKIM-1 and serum creatinine was calculated $(100.00 \%, 86.67 \%$ and $33.33 \%$; $95.00 \%)$ respectively. Conclusion: Preterm neonate with RDS is at high risk of developing AKI. Early and serial uKIM-1 measurements can be used as a non-invasive indicator of kidney injury in premature newborn with RDS.

"Corresponding author.

How to cite this paper: Youssef, M., Abdelsalam, M., Saeed, R. and Mohamed, A. (2016) Urinary Kidney Injury Molocule-1 Level in Preterm Neonates with Respiratory Distress Syndrome. Open Journal of Pediatrics, 6, 1-9. 


\title{
Keywords
}

\author{
Premature, Respiratory Distress Syndrome, Urinary Kidney Injury Molocule-1, Acute Kidney \\ Injury
}

\section{Introduction}

Respiratory distress syndrome, also known as hyaline membrane disease, occurs almost exclusively in premature infants. The incidence and severity of respiratory distress syndrome (RDS) are related inversely to the gestational age of the newborn infant (Pramanik et al., 2015) [1].

AKI incidence in patients with RDS was $29.5 \%$. Incidence of AKI was $38 \%$ among premature infants at 27 to 34 weeks of gestational age. Approximately one-third of preterm infants with RDS faced the risk of AKI (Genc et al., 2013) [2].

Acute kidney injury is typically diagnosed by measuring serum creatinine. Unfortunately; creatinine increase is a delayed and unreliable indicator of AKI (Clerico et al., 2012) [3].

Serum creatinine varies with age, sex, muscle bulk, metabolism, drugs and hydration status. It will not change until $>50 \%$ of kidney function has already been lost (Deverajan, 2007) [4].

Identifying biomarkers, to enable early and sensitive detection of AKI, has attracted the attention of recent research. An early detection could provide improvement in patient outcomes (Parikh et al., 2010; Bagshaw and Bellomo, 2007) [5] [6].

Urine is an excellent source of biomarkers in kidney disease because it has been estimated that normally $70 \%$ of the urinary proteins originate from the kidney and the urinary tract (Thongboonkerd and Malasit, 2005) [7].

Lines of evidence showed that urinary NGAL, IL-18, Cys-C, KIM-1 and some other candidate molecules were believed as potential markers to the diagnosis of AKI (Adiyanti and Loho, 2012; Edelstein, 2008) [8] [9]. But until now, none of them are currently established well enough to replace serum creatinine as a marker of renal function. Among various kinds of these markers, growing evidence showed that KIM-1 performed significant superiority in early detection of AKI than others, especially within 24 hours, before serum creatinine increases, which made it possible to conduct prevention or treatment strategies at a very early stage of AKI (Liangos et al., 2009; Han et al., 2008) [10] [11].

KIM-1 is a type I transmembrane protein and is highly up-regulated in the proximal tubule epithelial cells. KIM-1 mRNA and protein are expressed at a low level in normal kidney but are increased in post ischemic kidney (Stojanović et al., 2014) [12]. Urinary KIM-1 levels are strongly related to tubular KIM-1 expression in experimental and in human renal disease (Waanders et al., 2010) [13].

\section{Subjects and Methods}

This is a case control study was carried out on (30) preterm neonates $\leq 36$ weeks with respiratory distress syndrome. RDS was diagnosed according to clinical and radiographic criteria with typical chest radiographs (air bronchograms and reticulogranular infiltration) with respiratory and/or metabolic acidosis at birth or within several hours after delivery (Avery et al., 2005) [14]. Also it included 30 preterm neonates $\leq 36$ weeks as a control group. They were selected from NICU of Manshiate Elbakry hospital Cairo, Egypt, during the period from October 2014 to March 2015. Full term newborn, premature with: severe asphyxia, neonatal sepsis, multiple congenital anomalies including renal or any other congenital anomalies, inborn error of metabolism, newborn experienced exchange transfusion, extreme low birth weight and also newborn to the mother who suffered from chronic kidney disease were excluded from the study. Informed consent was obtained from the participating parents in adherence with the guidelines of the ethical committee of AL-Zahraa hospital, AL-Azher University, Cairo, Egypt.

The followings were done for all the studied neonates:

1) Full history taking including: Prenatal history including maternal condition during pregnancy (hypertention, PROM or DM...). Natal history includes mode and duration of delivery. Post natal history including 1st cry, cyanosis, Apgar score at one minute 5, and 10 minutes, urine output, medications, sleepiness, respiratory distress and convulsion. 
2) Clinical examination: Full general and local examination including: gestational age assessment using New Ballard Score (Ballard et al., 1991) [15]. Anthropometric measures, clinical features of respiratory distress such as tachypnea, grunting, retractions and cyanosis. Arterial blood gases (ABG): using Gen Dremier 3000.

\subsection{Sampling}

\section{a) Blood sample collection:}

- $3 \mathrm{ml}$ of venous blood were withdrawn; $1 \mathrm{ml}$ was collected on EDTA for CBC estimation.

- $2 \mathrm{ml}$ were collected into plan tube, left to clot then prompt separation of serum was done for BUN and Serum creatinine, were done on the same day.

- $0.5 \mathrm{ml}$ was taken on heparinized syringe from pre-warmed heel at birth for (ABG).

b) Urine sample collection:

Urine: Aseptically collection of the urine by using a urine bag. It is a plastic bag with a sticky strip on one end, made to fit over our baby's genital area. Open this bag and place it on the infant.

- For males, place the entire penis in the bag and attach the adhesive to the skin.

- For females, place the bag over the two folds of skin on either side of the vagina (labia).

Put a diaper on the baby (over the bag). Check the infant often, and change the bag after the infant has urinated. Empty the urine from the bag into a sterile container (Neil et al., 2013) [16]. Assay immediately, or aliquot and store at $\leq-20^{\circ} \mathrm{C}$, till the time of assay (avoid repeated freeze-thaw cycles).

\subsection{Routine Investigations}

1) Complete blood count (CBC) with differential leucocytes count: using Sysmex Kx 21.

2) Serum creatinine was estimated in day 1 and day 3 of life: using HITACHII auto analyzer.

3) C-reactive protein (CRP): using Integra $E 400$.

4) Arterial blood gases (ABG): using Gen Dremier 3000.

5) Radiological investigation: chest $x$ ray: used to detect RDS.

\subsection{Specific Investigations}

- Urinary kidney injury molecule-1 (uKIM-1) by ELIZA, it was done in day 1 (within the first 24 hour of admission) and in day 3 of life.

- eGFR $\mathrm{ml} / \mathrm{min} / 1.73 \mathrm{~m}^{2}$ (estimated in day 1 and day 3 of admission), eGFR = Kx height $(\mathrm{cm}) / \mathrm{P}_{\mathrm{Cr}}$ (Schwartz et al., 1987) [17].

\subsection{Principle of Test for KIM-1}

- This assay employs the quantitative sandwich enzyme immunoassay technique. A monoclonal antibody specific for human KIM-1 has been pre-coated onto a micro-plate. Standards and samples are pipetted into the wells and any TIM-1 present is bound by the immobilized antibody. After washing away any unbound substances, an enzyme-linked polyclonal antibody specific for human KIM-1 is added to the wells. Following a wash to remove any unbound antibody-enzyme reagent, a substrate solution is added to the wells and color develops in proportion to the amount of TIM-1 bound in the initial step. The color development is stopped and the intensity of the color is measured (https://resources.rndsystems.com/pdfs/datasheets/dkm100.pdf) [18].

\subsection{Study Limitation}

Small sample size, the relatively small number of studies and heterogeneity between them are the study limitation.

\subsection{Statistical Analysis}

Data collected and analyzed by computer program SPSS “Statistical Package for Social Science 1993” version 16. 
Qualitative data were presented as number and percentages while quantitative data were presented as mean, standard deviations and ranges. Independent (unpaired) student t-test was used to determine significance for numeric variable between two groups.

Person's correlation was used in each group for numeric variables.

Chi-square test was performed to determine significance between non parametric variables.

Roc curve analysis was done to determine sensitivity, specificity, cut off point, positive and negative predictive values.

The P-value was considered significant as the following:

P-value > 0.05: non-significant.

P-value < 0.05: significant.

P-value $<0.01$ : highly significant.

\section{Results}

Table 1: Comparison between preterm with RDS and their controls regarding demographic data and anthropometric measurements it revealed: significant decrease in Apgar at 1 and 5 minutes, $\mathrm{PH}, \mathrm{PO}_{2}$ and $\mathrm{HCO}_{3}$ in preterm with RDS with $(\mathrm{p}=0.001)$, with significant increase in $\mathrm{PCO}_{2}$ in preterm with RDS compared to the control group with $(\mathrm{p}=0.004)$.

Table 2: Comparison between preterm with RDS and their controls regarding (BUN, serum creatinine and eGFR) in day 1 of life it revealed; significant increase in uKIM-1 in preterm with RDS compared to their controls $(\mathrm{p}=0.001)$,but there was no significant difference between both groups regarding BUN, serum creatinine and eGFR.

Table 3: Comparison between (day 1 and day 3) of life in preterm with RDS and between survivors and

Table 1. Comparison between preterm with RDS and their controls regarding demographic data and anthropometric measurements.

\begin{tabular}{|c|c|c|c|c|c|c|c|}
\hline \multirow{2}{*}{\multicolumn{2}{|c|}{ Variable }} & \multicolumn{2}{|c|}{ Pre term Control group $(n=30)$} & \multicolumn{2}{|c|}{ Pre term RDS group $(n=30)$} & \multicolumn{2}{|c|}{ Chi square test } \\
\hline & & Mean \pm SD & Range & Mean \pm SD & Range & $X^{2} / t$ & p-value \\
\hline \multicolumn{2}{|c|}{ Gestational age $\{\mathrm{GA}\}$ (WK) } & $35.73 \pm 0.45$ & $(35-36)$ & $35.43 \pm 0.679$ & $(34-36)$ & -2.018 & 0.058 \\
\hline \multicolumn{2}{|c|}{ Birth Weight $\{\mathrm{BW}\}$ (Kg) } & $2.49 \pm 0.96$ & $(2.3-2.7)$ & $2.40 \pm 0.21$ & $(2.1-2.7)$ & -2.093 & 0.051 \\
\hline \multicolumn{2}{|c|}{ Birth length $\{\mathrm{BL}\}(\mathrm{cm})$} & $45.77 \pm 1.22$ & $(44-48)$ & $44.87 \pm 2.315$ & $(40-48)$ & -1.883 & 0.065 \\
\hline \multicolumn{2}{|c|}{ Head circumference $\{\mathrm{HC}\}(\mathrm{cm})$} & $33.96 \pm 0.67$ & $(33-35)$ & $33.38 \pm 1.99$ & $(25-35.5)$ & 1.513 & 0.153 \\
\hline \multirow{2}{*}{$\begin{array}{l}\text { Gender } \\
\{n(\%)\}\end{array}$} & Male & 14 & $46.5 \%$ & 15 & $50 \%$ & \multirow{2}{*}{0.258} & \multirow{2}{*}{0.795} \\
\hline & Female & 16 & $53.5 \%$ & 15 & $50 \%$ & & \\
\hline \multirow{2}{*}{ Apgar } & $1 \mathrm{~min}$ & $7.30 \pm 0.75$ & $(6-8)$ & $5.87 \pm 1.28$ & $(3-7)$ & 5.280 & 0.001 \\
\hline & $5 \mathrm{~min}$ & $8.96 \pm 0.18$ & $(8-9)$ & $8.37 \pm 0.96$ & $(6-9)$ & 3.309 & 0.001 \\
\hline \multirow{4}{*}{ Blood-gases } & $\mathrm{PH}$ & $7.39 \pm 0.02$ & $7.34-7.43$ & $7.32 \pm 0.08$ & $7.1-7.49$ & 4.524 & 0.001 \\
\hline & $\mathrm{PCO}_{2}(\mathrm{mmHg})$ & $39.75 \pm 2.02$ & $36.5-44$ & $42.89 \pm 5.29$ & $36-56$ & -3.034 & 0.004 \\
\hline & $\mathrm{pO}_{2}(\mathrm{mmHg})$ & $78.52 \pm 28.40$ & $45-154$ & $45.74 \pm 4.53$ & $35.3-55$ & 6.242 & 0.000 \\
\hline & $\mathrm{HCO}_{3}(\mathrm{mmol} / \mathrm{L})$ & $22.82 \pm 0.49$ & $22-23.6$ & $18.79 \pm 4.29$ & $10.2-28.2$ & 5.119 & 0.000 \\
\hline
\end{tabular}

Table 2. Comparison between preterm with RDS and their controls regarding (BUN, serum creatinine and eGFR) in day 1 of life.

\begin{tabular}{ccccccc}
\hline Variable & \multicolumn{2}{c}{ Pre term Control group $(\mathbf{n}=\mathbf{3 0})$} & \multicolumn{2}{c}{ Pre term RDS group $(\mathbf{n}=30)$} & \multicolumn{2}{c}{ Chi square test } \\
\cline { 2 - 6 } & Mean \pm SD & Range & Mean \pm SD & Range & t & p-value \\
\hline BUN in day 1 $(\mathrm{mg} / \mathrm{dl})$ & $14.97 \pm 0.36$ & $(14-16)$ & $18.86 \pm 6.67$ & $(9-24)$ & 3.189 & 0.05 \\
Creat. in day 1 $(\mathrm{mg} / \mathrm{dl})$ & $0.58 \pm 0.08$ & $(0.5-0.7)$ & $0.65 \pm 0.18$ & $(0.5-1.3)$ & 1.946 & 0.056 \\
eGFR in day 1 $\left(\mathrm{ml} / \mathrm{min} / 1.73 \mathrm{~m}^{2}\right)$ & $26.38 \pm 3.65$ & $(21.21-31.20)$ & $24.25 \pm 5.27$ & $(11.17-31.02)$ & -1.817 & 0.074 \\
KIM-1 in day 1 $(\mathrm{ng} / \mathrm{ml})$ & $0.95 \pm 0.52$ & $(0.18-2.3)$ & $2.88 \pm 1.01$ & $(1.6-5.6)$ & 9.306 & 0.001 \\
\hline
\end{tabular}


non-survivors groups regarding BUN, serum creatinine, eGFR and uKIM it revealed: significant increase in uKIM-1 in day 1 compared to day 3 life in non survivors than survivors group, while there was no significant differences regarding BUN, serum creatinine and eGFR.

Figure 1, Figure 2: Demonstrate uKIM-1 distribution in the preterm with RDS in day 1 and day 3 of life, it revealed that $96.7 \%$ and $33.3 \%$ of them respectively had a high level of uKIM-1 more than the calculated cut off point.

Table 4 and Table 5, Figure 3: The cut off point of uKIM level was $>1.5$ between preterm with RDS and their controls with sensitivity (100.00\%) and specificity (100.00\%), while the sensitivity and specificity of eGFR and

Table 3. Comparison between BUN, serum creatinine, eGFR and uKIM-1 in day 1 and day 3 of life in preterm with RDS group and uKIM-1 level between survivors and non-survivors groups.

\begin{tabular}{|c|c|c|c|c|c|}
\hline \multirow{2}{*}{\multicolumn{2}{|c|}{ Variable }} & \multicolumn{2}{|c|}{ Pre term RDS group $(n o=30)$} & \multicolumn{2}{|c|}{ Chi square test } \\
\hline & & Mean \pm SD & Range & $\mathbf{t}$ & p-value \\
\hline \multirow{2}{*}{$\begin{array}{c}\text { BUN } \\
(\mathrm{mg} / \mathrm{dl})\end{array}$} & day 1 & $18.86 \pm 6.67$ & $(9-43)$ & \multirow[b]{2}{*}{0.466} & \multirow[b]{2}{*}{0.643} \\
\hline & day 3 & $18.10 \pm 5.93$ & $(11.5-35.5)$ & & \\
\hline \multirow{2}{*}{$\begin{array}{l}\text { Creatinine } \\
\text { (mg/dl) }\end{array}$} & day 1 & $0.65 \pm 0.18$ & $(0.5-1.3)$ & \multirow{2}{*}{0.938} & \multirow{2}{*}{0.352} \\
\hline & day 3 & $0.70 \pm 0.23$ & $(0.5-1.3)$ & & \\
\hline \multirow{2}{*}{$\begin{array}{c}\text { eGFR } \\
\left(\mathrm{ml} / \mathrm{min} / 1.73 \mathrm{~m}^{2}\right)\end{array}$} & day 1 & $23.23 \pm 5.66$ & $(11.15-31.02)$ & \multirow{2}{*}{0.051} & \multirow{2}{*}{0.960} \\
\hline & day 3 & $23.31 \pm 6.01$ & $(11.13-31.68)$ & & \\
\hline \multirow{6}{*}{ uKIM-1 (ng/ml) } & day 1 & $2.88 \pm 1.01$ & $(1.6-5.6)$ & \multirow{2}{*}{4.240} & \multirow{2}{*}{0.001} \\
\hline & day 3 & $1.63 \pm 1.26$ & $(0.2-5.1)$ & & \\
\hline & & Survivors no. 22 & Non-survivors no. 8 & & \\
\hline & & Mean \pm SD & Mean \pm SD & $\mathrm{t}$ & P-value \\
\hline & day 1 & $2.86 \pm 0.99$ & $2.95 \pm 1.14$ & 0.212 & 0.834 \\
\hline & day 3 & $1.30 \pm 0.90$ & $2.30 \pm 1.56$ & 2.197 & 0.037 \\
\hline
\end{tabular}

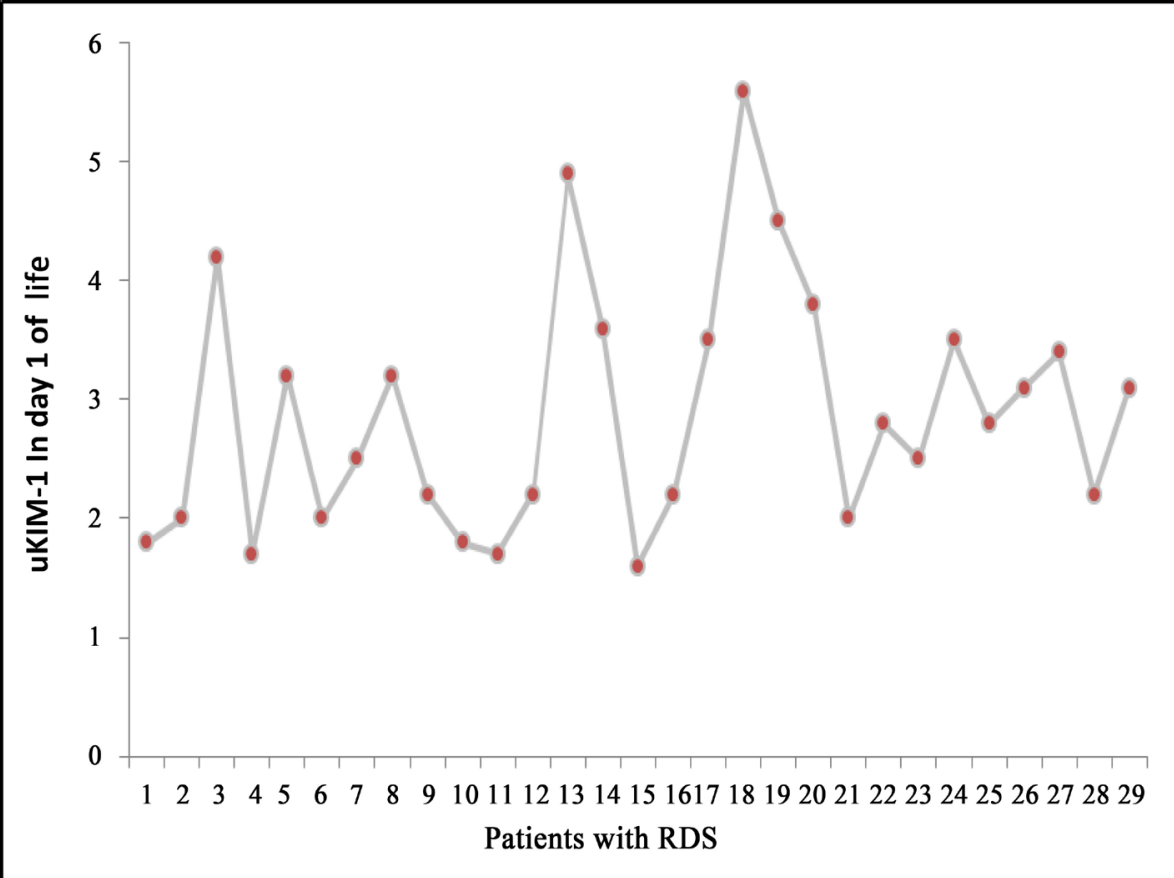

Figure 1. uKIM-1 distribution in the studied cases in day 1 of life. 


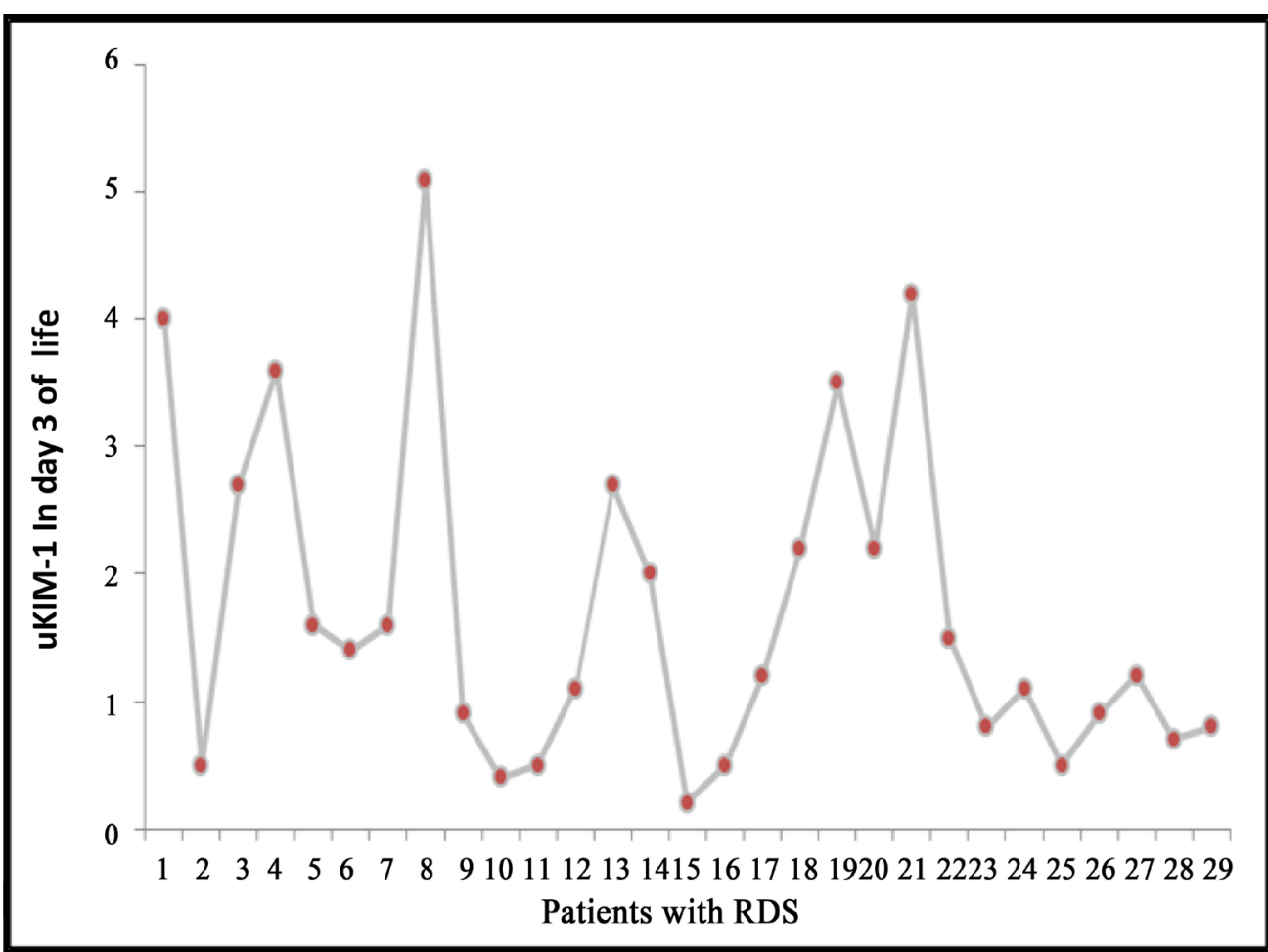

Figure 2. uKIM-1 distribution in the studied cases in day 3 of life.

Table 4. Correlations and the relations between uKIM-1 level and (GA, gender, type of o2 therapy, eGFR, BUN and serum creat).

\begin{tabular}{|c|c|c|c|}
\hline \multirow{2}{*}{\multicolumn{2}{|c|}{ Variable }} & \multicolumn{2}{|c|}{ uKIM-1 (ng/ml) Pre term RDS group } \\
\hline & & $\mathbf{r}$ & p-value \\
\hline \multicolumn{2}{|c|}{ GA (weeks) } & -0.163 & 0.389 \\
\hline \multicolumn{2}{|c|}{ eGFR $\left(\mathrm{ml} / \mathrm{min} / 1.73 \mathrm{~m}^{2}\right)$} & -0.077 & 0.685 \\
\hline \multicolumn{2}{|c|}{ BUN (mg/dl) } & 0.153 & 0.420 \\
\hline \multicolumn{2}{|c|}{ Creat (mg/dl) } & 0.265 & 0.157 \\
\hline \multirow{2}{*}{ Gender } & Female (no. 15) & $\mathbf{t}$ & p-value \\
\hline & Male (no. 15) & 0.084 & 0.934 \\
\hline \multirow{2}{*}{ Mode of delivery } & CS No. 25 & \multirow{2}{*}{0.063} & \multirow{2}{*}{0.950} \\
\hline & NVD No.5 & & \\
\hline & SIMV No.15 & & \\
\hline \multirow[t]{2}{*}{ Oxygen therapy } & N.CPAP No.15 & 1.448 & 0.253 \\
\hline & N.P. No.5 & & \\
\hline
\end{tabular}

Cs: cesarean; NVD: normal vaginal delivery; SIMV: Synchronized Intermittent Mandatory Ventilation; CPAP: continuous positive airway pressure N.P: nasal prong.

Table 5. Cut-off point, sensitivity and specificity of eGFR, serum creatinine and uKIM-1 in detection of AKI in the preterm with RDS.

\begin{tabular}{ccccccc}
\hline Variable & Cut-off point & AUC & Sensitivity $\%$ & Specificity\% & + PV & $-\mathbf{P V}$ \\
\hline eGFR ml/min/1.73m ${ }^{2}$ ) & $<21.19$ & 67.4 & 36.67 & 100.00 & 100.00 & 61.27 \\
sCreat mg/dl & $>0.7$ & 57.6 & 33.33 & 95.00 & 86.96 & 58.78 \\
uKIM-1 & $>1.5$ & 0.975 & 100.00 & 86.67 & 88.2 & 100.0 \\
\hline
\end{tabular}




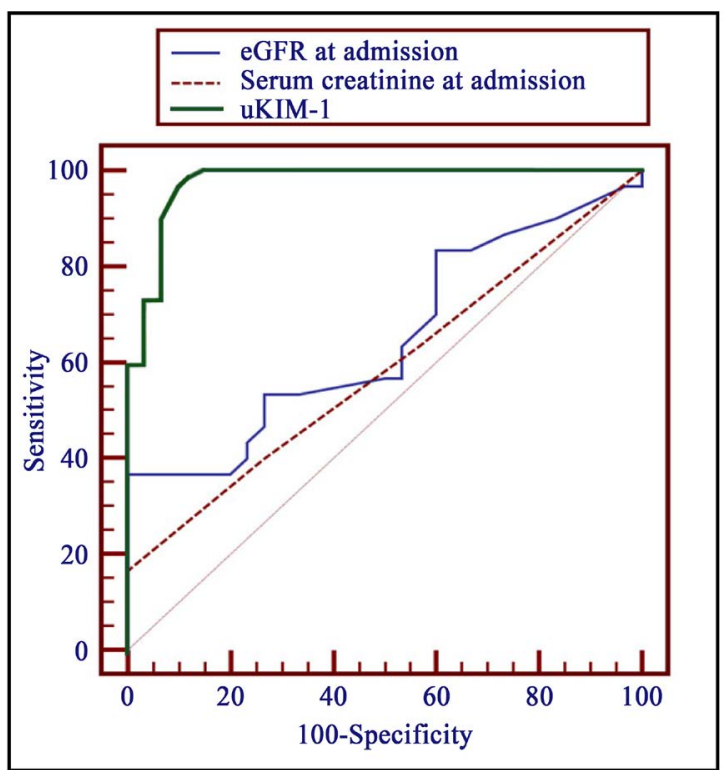

Figure 3. Cut-off point, sensitivity and specificity of eGFR, S. creatinine and uKIM-1 in detection of AKI.

serum creatinine were (36.67\%, 100.00\%; 33.33\%, 95.00\%) respectively.

\section{Discussion}

Because the incidence of AKI is still high, the outcome remains poor and preterm with RDS population remains at especially high risk of having AKI, in order to enhance the ability to predict the occurrence of AKI and facilitate timely introduction of AKI-specific therapies, more and more efforts were made to discover novel urinary biomarkers prior to serum creatinine (Lattanzio and Kopyt, 2009) [19].

Accordingly, we are focused on identifying new biomarkers able to anticipate the AKI diagnosis in hours or even days before a UO reduction or SCr increment can be detected.

We evaluated urinary kidney injury molecule-1 (KIM-1) as a marker of acute kidney injury (AKI) in preterm neonates with RDS in day 1 and day 3 of life in the same line with of eGFR and S. creatinine. It is surprisingly to find that the incidence of AKI in neonates with RDS in day 1 is $96.7 \%$. In comparison to day 3 of life, it is reported in our study to be $33.3 \%$. The incidence of AKI in neonates with RDS is reported to be in the range of 25\% to 66\% (Mortazavi et al., 2009; Li et al., 2012) [20] [21]. Due to incomplete nephrogenesis and low numbers of nephrons, as well as additional conditions such as RDS, preterm neonates are at risk of AKI (Koralkar, 2011, Hentschel, 1996; Rodriguez-Soriano et al., 2005) [22]-[24].

uKIM-1 plays a major role in the restoration of structural and functional integrity following kidney damage so it's levels in neonates were higher in the day 1 of life and systematically decreased (Roszkowska-Blaim and Kisiel, 2013) [25]. And this might explain the highest level of uKIM-1 in preterm with RDS in day 1 of life. These results suggested that right time adoption could remarkably increase the success of AKI diagnosis.

Liang et al. [26] found that uKIM-1 was associated with the occurrence of AKI but uKIM-1 was unrelated to the progression of AKI.

Our results are in agreement with Genc et al. [27] who reported that uKIM-1 in day $1 \mathrm{in}$ (ng/ml): in control $(2.8 \pm 1.1)$, in RDS $(6.9 \pm 4.9)$, with P-value $=0.003$. Renal function should be routinely monitored in neonates for safe dosing of medications, as well as tracking hydration status and various renal pathologies (Bartelink et al., 2007) [28]. GFR is widely used as a reliable measure of kidney function and kidney disease progression (Filler et al., 2003) [29]. Also high serum creatinine levels (Cr) are widely used in the diagnosis of AKI (Mehta et al., 2007; Hoste and Kellum, 2006) [30] [31].

However, we did not find any significant change in S.Cr levels and in estimated GFR in neonates with RDS compared to controls in day 1 of life and even among RDS group in day 1 and day 3 of life, Cr cannot be applied to neonates for the first few postnatal days (PND), because serum $\mathrm{Cr}$ reflects maternal kidney function during this period (Gallini et al., 2000; Brion et al., 1986) [32] [33]. In addition, distribution of normal SCr val- 
ues, which varies greatly, depending on the level of prematurity and age (Aggarwal et al., 2005; Libório et al., 2014) [34] [35]. And unfortunately, newborns can be oliguric in the first day of life. We found no association between uKIM-1 levels and GA, gender, mode of delivery and type o2 therapy.

In our study, we evaluated uKIM-1 in survivor and non-survivor. Our results showed significantly higher uKIM-1 concentrations in the non-survivor subgroup, indicating the relation to the adverse outcome. (Liangos et al., 2007) [36] reported that uKIM-1 had a predictive value for adverse clinical outcome such as dialysis requirement or hospital death and multiorgan failure.

We calculated the cut off point, sensitively and specificity of eGFR, serum creatinine and uKIM-1 in detection of AKI, it is accepted to find that both serum Cr and eGFR are highly specific with poor sensitively and it is fortunately to report in this study that uKIM- 1 is highly specific $100 \%$ and sensitive $86 \%$ and the cut of point uKIM-1 > $1.5(\mathrm{ng} / \mathrm{ml})$, so we propose that uKIM-1 is predictive of subsequent development of AKI in preterm neonates with RDS. Therefore, we concluded that uKIM have a significant diagnostic value on the first day of life in preterm with RDS and serial uKIM-1 measurements can be used for follow-up in premature newborn with RDS, however more studies with a larger sample size are thus needed to further elucidate the diagnostic value of KIM-1 for AKI.

\section{References}

[1] Pramanik, A.K., Rosenkrantz, T. and Clark, D.A. (2015) Respiratory Distress Syndrome. http://emedicine.medscape.Com/article/976034-overview

[2] Genc, G., Ozkaya, O., Avci, B., Aygun, C. and Kucukoduk, S. (2013) Kidney Injury Molecule-1 as a Promising Biomarker for Acute Kidney Injury in Premature Babies. American Journal of Perinatology, 30, 245-252.

[3] Clerico, A., Galli, C., Fortunato, A. and Ronco, C. (2012) Neutrophil Gelatinase-Associated Lipocalin (NGAL) as Biomarker of Acute Kidney Injury: A Review of the Laboratory Characteristics and Clinical Evidences. Clinical Chemistry and Laboratory Medicine (CCLM), 50, 1505-1517. http://dx.doi.org/10.1515/cclm-2011-0814

[4] Devarajan, P. (2011) Biomarkers for the Early Detection of Acute Kidney Injury. Current Opinion in Pediatrics, 23, 194. http://dx.doi.org/10.1097/mop.0b013e328343f4dd

[5] Parikh, C.R., Lu, J.C., Coca, S.G. and Devarajan, P. (2010) Tubular Protein-Uria in Acute Kidney Injury: A Critical Evaluation of Current Status and Future Promise. Annals of Clinical Biochemistry, 47, 301-312. http://dx.doi.org/10.1258/acb.2010.010076

[6] Bagshaw, S.M. and Bellomo, R. (2007) Early Diagnosis of Acute Kidney Injury. Current Opinion in Critical Care, 13, 638-644. http://dx.doi.org/10.1097/MCC.0b013e3282f07570

[7] Thongboonkerd, V. and Malasit, P. (2005) Renal and Urinary Proteomics: Current Applications and Challenges. Proteomics, 5, 1033-1042. http://dx.doi.org/10.1002/pmic.200401012

[8] Adiyanti, S.S. and Loho, T. (2012) Acute Kidney Injury (AKI) Biomarker. Acta Medica Indonesiana, 44, $246-255$.

[9] Edelstein, C.L. (2008) Biomarkers of Acute Kidney Injury. Advances in Chronic Kidney Disease, 15, 222-234. http://dx.doi.org/10.1053/j.ackd.2008.04.003

[10] Liangos, O., Tighiouart, H., Perianayagam, M.C., Kolyada, A., Han, W.K., et al. (2009) Comparative Analysis of Urinary Biomarkers for Early Detection of Acute Kidney Injury Following Cardiopulmonary Bypass. Biomarkers, 11, 423-431. http://dx.doi.org/10.1080/13547500903067744

[11] Han, W.K., Waikar, S.S., Johnson, A., Betensky, R.A., Dent, C.L., et al. (2008) Urinary Biomarkers in the Early Diagnosis of Acute Kidney Injury. Kidney International, 73, 863-869. http://dx.doi.org/10.1038/sj.ki.5002715

[12] Stojanović, V.D., Vučković, N.M., Barišić, N.A., Srdić, B., Doronjski, A.D. and Antić, A.E.P. (2014) Early Biomarkers of Renal Injury and Protective Effect of Erythropoietin on Kidneys of Asphyxiated Newborn Rats. Pediatric Research, 76, 11-16. http://dx.doi.org/10.1038/pr.2014.50

[13] Waanders, F., van Timmeren, M.M., Stegeman, C.A., Bakker, S.J. and van Goor, H. (2010) Kidney Injury Molecule-1 in Renal Disease. The Journal of Pathology, 220, 7-16. http://dx.doi.org/10.1002/path.2642

[14] Avery, G.B., MacDonald, M.G., Seshia, M.M.K. and Mullett, M.D. (2005) Avery’s Neonatology: Pathophysiology and Management of the Newborn. 6th Edition, Lippincott Williams \& Wilkins, Philadelphia.

[15] Ballard, J.L. and Khoury, J.C. (1991) New Ballard Score, Expanded to Include Extremely Premature Infants. Journal of Pediatrics, 119, 417-423. http://dx.doi.org/10.1016/S0022-3476(05)82056-6

[16] Kaneshiro, N.K. (2013) Urine Collection-Infants. A.D.A.M., Inc. Is Accredited by URAC, Also Known as the American Accreditation Health Care Commission. http://www.urac.org 
[17] Schwartz, G.J., Brion, L.P. and Spitzer, A. (1987) The Use of Plasma Creatinine Concentration for Estimating Glomerular Filtration Rate in Infants, Children, and Adolescents. Pediatric Clinics of North America, 34, 571-590.

[18] https://resources.rndsystems.com/pdfs/datasheets/dkm100.pdf.

[19] Lattanzio, M.R. and Kopyt, N.P. (2009) Acute Kidney Injury: New Concepts in Definition, Diagnosis, Pathophysiology, and Treatment. The Journal of the American Osteopathic Association, 109, 13-19.

[20] Mortazavi, F., Hosseinpour Sakha, S. and Nejati, N. (2009) Acute Kidney Failure in Neonatal Period. Iranian Journal of Kidney Diseases, 3, 136-140.

[21] Li, Y., Fu, C., Zhou, X., Xiao, Z., Zhu, X., Jin, M., Li, X. and Feng, X. (2012) Urine Interleukin-18 and Cystatin-C as Biomarkers of Acute Kidney Injury in Critically Ill Neonates. Pediatric Nephrology, 27, 851-860. http://dx.doi.org/10.1007/s00467-011-2072-x

[22] Koralkar, R., Ambalavanan, N., Levitan, E.B., McGwin, G., Goldstein, S. and Askenazi, D. (2011) Acute Kidney Injury Reduces Survival in Very Low Birth Weight Infants. Pediatric Research, 69, 354-358. http://dx.doi.org/10.1203/PDR.0b013e31820b95ca

[23] Hentschel, R., Lodige, B. and Bulla, M. (1996) Renal Insufficiency in the Neonatal Period. Clinical Nephrology, 46, 54-58.

[24] Rodriguez-Soriano, J., Aguirre, M., Oliveros, R. and Vallo, A. (2005) Long-Term Renal Follow-Up of Extremely Low Birth Weight Infants. Pediatric Nephrology, 20, 579-584. http://dx.doi.org/10.1007/s00467-005-1828-6

[25] Roszkowska-Blaim, M. and Kisiel, A. (2013) Role of Biomarkers in the Early Diagnosis of Acute Kidney Injury in Neonates. Postepy Nauk Medycznych, 24, 138-143.

[26] Liang, X.L., Liu, S.X., Chen, Y.H., et al. (2010) Combination of Urinary Kidney Injury Molecule-1 and Interleukin-18 as Early Biomarker for the Diagnosis and Progressive Assessment of Acute Kidney Injury Following Cardiopulmonary Bypass Surgery: A Prospective Nested Case-Control Study. Biomarkers, 15, 332-339. http://dx.doi.org/10.3109/13547501003706558

[27] Genc, G., Ozkaya, O., Avci, B., Aygun, C. and Kucukoduk, S. (2013) Kidney Injury Molecule-1 as a Promising Biomarker for Acute Kidney Injury in Premature Babies. American Journal of Perinatology, 30, 245-252.

[28] Bartelink, I.H., Rademaker, C.M., Schobben, A.F. and van den Anker, J.N. (2006) Guidelines on Paediatric Dosing on the Basis of Developmental Physiology and Pharmacokinetic Considerations. Clinical Pharmacokinetics, 45, 10771097. http://dx.doi.org/10.2165/00003088-200645110-00003

[29] Filler, G., Browne, R. and Seikaly, M.G. (2003) Glomerular Filtration Rate as a Putative "Surrogate End-Point” for Renal Transplant Clinical Trials in Children. Pediatric Transplantation, 7, 18-24. http://dx.doi.org/10.1034/j.1399-3046.2003.00015.x

[30] Mehta, R.L., Kellum, J.A., Shah, S.V., Molitoris, B.A. and Ronco, C. (2007) Acute Kidney Injury Network: Report of an Initiative to Improve Outcomes in Acute Kidney Injury. Critical Care, 11, R31. http://dx.doi.org/10.1186/cc5713

[31] Hoste, E.A. and Kellum, J.A. (2006) RIFLE Criteria Provide Robust Assessment of Kidney Dysfunction and Correlate with Hospital Mortality. Critical Care Medicine, 34, 2016-2017. http://dx.doi.org/10.1097/01.CCM.0000219374.43963.B5

[32] Gallini, F., Maggio, L., Romagnoli, C., Marrocco, G. and Tortorolo, G. (2000) Progression of Renal Function in Preterm Neonates with Gestational Age $\leq 32$ Weeks. Pediatric Nephrology, 15, 119-124. http://dx.doi.org/10.1007/s004670000356

[33] Brion, L.P., Fleischman, A.R., McCarton, C. and Schwartz, G.J. (1986) A Simple Estimate of Glomerular Filtration Rate in Low Birth Weight Infants during the First Year of Life: Noninvasive Assessment of Body Composition and Growth. Journal of Pediatrics, 109, 698-707. http://dx.doi.org/10.1016/S0022-3476(86)80245-1

[34] Aggarwal, A., Kumar, P., Chowdhary, G., Majumdar, S. and Narang, A. (2005) Evaluation of Renal Functions in Asphyxiated Newborns. Journal of Tropical Pediatrics, 51, 295-299. http://dx.doi.org/10.1093/tropej/fmi017

[35] Libório, A.B., Branco, K.M.P.C. and Torres, D.M. (2014) Acute Kidney Injury in Neonates: From Urine Output to New Biomarkers. BioMed Research International, 2014, Article ID: 601568.

[36] Liangos, O., Perianayagam, M.C., Vaidya, V.S., et al. (2007) Urinary N-Acetyl- $\beta$-(D)-Glucosaminidase Activity and Kidney Injury Molecule-1 Level Are Associated with Adverse Outcomes in Acute Renal Failure. Journal of the American Society of Nephrology, 18, 904-912. http://dx.doi.org/10.1681/ASN.2006030221 